\title{
Prevalence of latent tuberculosis infection among coal workers' pneumoconiosis patients in China: a cross-sectional study
}

\author{
Yan Jin ${ }^{1,2}$, Huanqiang Wang ${ }^{1}$, Jianfang Zhang ${ }^{3}$, Chunguang Ding ${ }^{3}$, Ke Wen ${ }^{1}$, Jingguang Fan ${ }^{3 *}$ and Tao Li ${ }^{*}$
}

\begin{abstract}
Background: Little is known about the prevalence of latent tuberculosis infection (LTBI) among coal workers' pneumoconiosis (CWP) patients. To estimate the prevalence of LTBI and identify its associated risk factors among CWP patients.

Methods: A cross-sectional study was conducted to assess the prevalence of LTBI. Participants were screened for active TB or a history of TB by X-ray and those that underwent QuantiFERON-TB Gold In-Tube (QFT) test. A standardized questionnaire was completed and risk factors were assessed for acquiring TB. Log-binomial regression was used to estimate the LTBI prevalence ratio (PR) in relation to risk factors.

Results: Of 244 individuals with CWP (median age 67 years; all male), 162 (66.4\%) were QFT positive. In Multivariate analysis, poor workplace ventilation (adjusted prevalence ratio $[A P R]=1.26$ ) and intake of fruits regularly ( $\geq 4$ days of every week) (APR $=0.81$ ) (all $p<0.05$ ) were associated with a decreased risk of QFT.

Conclusions: This study showed a high prevalence of LTBI among individuals with CWP in China. Poor workplace ventilation may be an important contributing factor for LTBI. Regular monitoring and dust control measures need to be improved in workplaces to ensure the safety of workers. Moreover, intake of fruits regularly may be a protective factor for LTBI. However, the effect of fruits should be further studied.
\end{abstract}

Keywords: Mycobacterium tuberculosis, IFN- $\gamma$, Occupational health

\section{Background}

China currently has one of the highest rates of pneumoconiosis in the world, with this disease accounting for over $85 \%$ of all reported occupational diseases in the country $[1,2]$. Coal workers' pneumoconiosis (CWP) is believed to be the predominant type, accounting for about $60 \%$ of the total number of new cases of pneumoconiosis $[1,2]$. Tuberculosis (TB) is the most common complication associated with CWP [3]. However, little is known about the prevalence of latent $\mathrm{TB}$ infections (LTBI) among CWP patients. A LTBI is defined as the presence of immune responses to Mycobacterium tuberculosis antigens without any clinical evidence of active

\footnotetext{
* Correspondence: fan-jg@263.net; litao@chinacdc.cn

${ }^{3}$ Research Center for Occupational Safety and Health, State Administration of Work Safety, Beijing, China

${ }^{1}$ National Institute of Occupational Health and Poison Control, Chinese

Center for Disease Control and Prevention, Beijing, China

Full list of author information is available at the end of the article
}

TB. Patients with LTBI are at risk of developing active TB disease and becoming infectious [4]. The risk of LTBI reactivation can be reduced by preventive treatment. Identification and treatment of LTBI in individuals at high risk of developing active disease has been practiced as an effective strategy for TB control in the US [5].

The World Health Organization has issued guidelines on the management of LTBI for a wide range of risk groups, including patients with HIV or silicosis [6]. There is no diagnostic gold standard test for LTBI, but M. tuberculosis-specific interferon (IFN)- $\gamma$-based diagnostic tests offer increased specificity $(93 \%-99 \%)$ and at least equivalent sensitivity $(75 \%-90 \%)$ as the tuberculin skin test (TST) and are unaffected by previous BCG vaccination [7]. In Norway, a limited number of studies on the results of IFN- $\gamma$ release assays (IGRAs) in various populations have been published [8-10], but no study 
has focused on CWP. Only one study has reported the prevalence of LTBI among aged underground hard coal miners using IGRAs in Germany [11]. The aim of the current study was to estimate the prevalence of LTBI using a T-cell-based IGRA in CWP patients and to determine the risk factors associated with a positive test result.

\section{Methods}

\section{Study participants}

This cross-sectional study was conducted from October to December, 2016, as part of a pneumoconiosis screening program at the Hospital of Occupational Diseases in Beijing. This hospital has seven wards specialized in pneumoconiosis, with a total capacity of 380 beds. Study participants were recruited from all the wards within the hospital. A total of 376 participants diagnosed CWP based on the China National Diagnostic Criteria for Pneumoconiosis by performing a full chest X-ray of good quality. Diagnoses were made independently by three certified doctors on the basis of occupational history, physical examination, chest radiograph and pulmonary function tests. All participants were acquired that had no history of $\mathrm{TB}$ and received a medical evaluation and chest $\mathrm{X}$-rays to exclude active TB.

\section{IGRA test}

Because there is no gold standard for the diagnosis of LTBI, we chose a T-cell-based IGRA for this study which was performed according to the manufacturer's instructions (QuantiFERON-TB Gold InTube, Cellestis Limited, Carnegie, Australia). A venous blood sample $(1 \mathrm{ml})$ was collected from each individual and aliquoted into three tubes (one containing TB-specific antigens, one containing mitogen and a negative control tube). The samples were transported within 4-6 h of collection and incubated for $24 \mathrm{~h}$ at $37{ }^{\circ} \mathrm{C}$. Then the samples were centrifuged at $3000 \times \operatorname{rcf}$ for $10 \mathrm{~min}$, and the plasma was collected and stored at $4{ }^{\circ} \mathrm{C}$ until the IGRA was performed using the enzyme-linked immunosorbent assay (ELISA) kit provided with the TB-Gold tube. The optical density (OD) of each sample was determined using a 450-nm filter and a 620-nm reference filter on an ELISA plate reader. The results were interpreted as positive, negative or indeterminate on the basis of the manufacturer's recommended cut-off values (IFN- $\gamma \geq 0.35 \mathrm{IU} / \mathrm{ml}$ ) using QuantiFERON-TB Gold In Tube (QFT) analysis software developed by the company.

\section{Questionnaire}

Information on the following variables was collected using a standardized questionnaire. Data obtained included, among others, age, BMI (body mass index), highest educational level, marital status and personal income. We also inquired about occupational factors including stages of CWP, job category, years of work, dust exposure period, age at first dust exposure and duration of dust exposure. We also assessed environmental and behavioral factors including, among others, workplace ventilation, accommodation, smoking and alcohol consumption. We also assessed family history of TB, close contact with patients with $\mathrm{TB}$ and BCG vaccination.

\section{Statistics}

QFT laboratory results and questionnaire data were entered into the EpiData software v3.1 (EpiData Association, Odense, Denmark) and were analyzed using SAS software (Version 9.4, SAS Institute, USA). Continuous variables were described by medians and interquartile range (IQR). Proportions were summarized for categorical variables. The prevalence of LTBI was estimated by dividing the number of participants with a positive QFT test result by the total number of participants. Logbinomial regression with a logarithmic link function was used to estimate prevalence ratios (PRs) with their 95\% confidence intervals; this was preferred to logistic regression as odds ratios tend to over-state effect sizes, particularly when prevalence is greater than $10 \%$ [12]. Bivariate analyses of each potential risk factor and LTBI were done first. Variables with $p$ values $<0.05$ in bivariate analyses were included in multivariate log-binomial regression analyses. The significance level for testing associations was set at 0.05 . All statistical tests were two tailed.

\section{Results}

In total, 376 patients admitted to the Hospital of Occupational Diseases and screened for pneumoconiosis from October to December 2016, were selected for this survey. Of these, 112 (29.8\%) were excluded owing to a previous history of TB. Of the remaining 264, 20 (5.3\%) did not volunteer to provide blood samples. Therefore, 244 (64.9\%) participants actually participated in the investigation and received the QFT test (Fig. 1). The participants were all male and ranged from 42 to 92 years, with a median age of 67 years. The BMI distribution showed that more than half of the participants (59.3\%) were overweight. About half of the participants (50.4\%) were of primary school or lower education level. Personal income per month showed that more than $70 \%$ of the participants earned between 3000 and 4000 RMB, and family income per head per month showed that 67 . $2 \%$ of the participants earned below 6000 RMB. About $90 \%$ of the participants were born in the countryside (Table 1).

The prevalence of LTBI in the 244 CWP patients, based on QFT positivity, was $66.4 \%$ (95\% CI: 61.0\%-72.9\%) (Additional file 1). The QFT response was negative in $32.8 \%$ of 


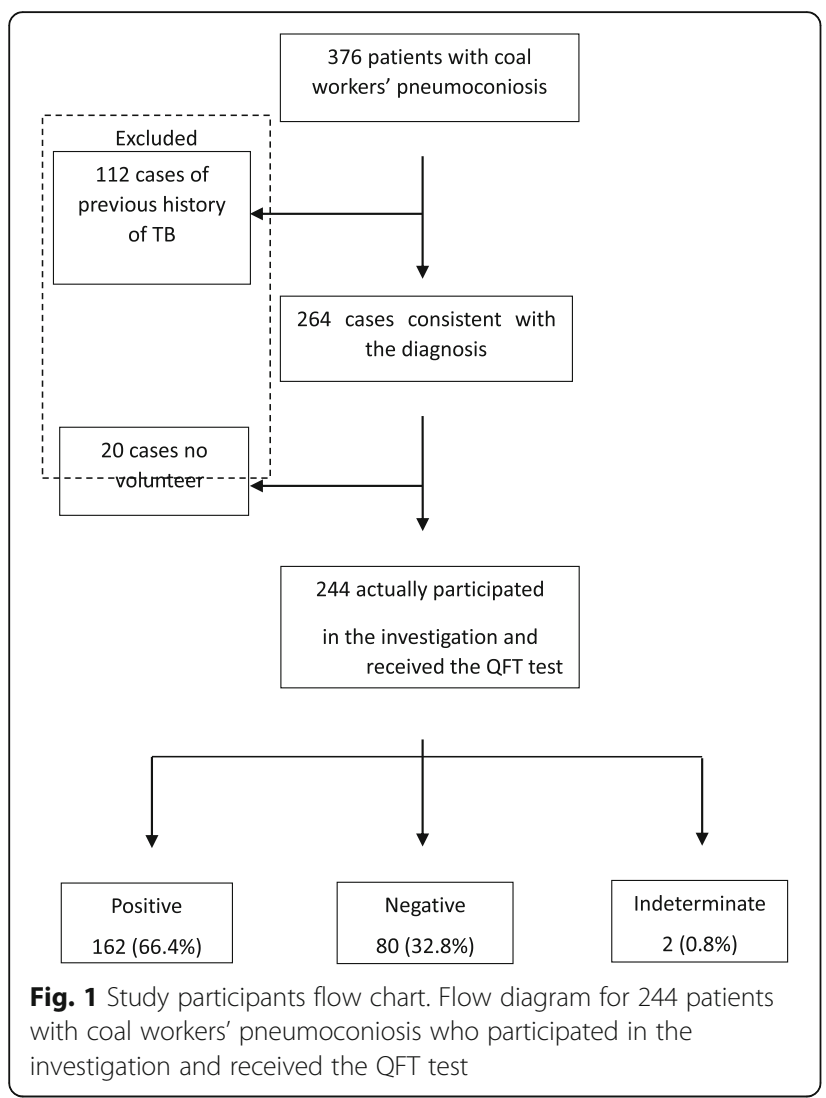

cases and was indeterminate in $0.8 \%$ (Fig. 1). Excluding two cases for which the QFT results were indeterminate, the remaining $242 \mathrm{CWP}$ cases were analyzed for risk factors. As shown in Table 2, there were no significant difference in the prevalence of LTBI in terms of socio-demographic characteristics and occupational factors. The environmental risk factor for QFT was workplace ventilation. Using the subgroup workplace ventilation as the reference group, the prevalence ratio $[\mathrm{PR}]$ was elevated for poor workplace ventilation (PR: 1.25; 95\% confidence interval [CI]: 1.04-1.51). The behavioral protective factor for QFT was intake of fruits regularly. Using the subgroup $<1$ day of every week of intake of fruit as the reference group, the risk of LTBI was reduced by $21 \%$ both for those eating fruit 1 to 3 days of every week (PR: 0.79; 95\% CI: 0.63-0.99) and those eating fruit $\geq 4$ days of every week (PR: 0 . 79; 95\% CI: 0.64-0.97).

Job category was included in multivariate log-binomial regression analyses because it was related to LTBI borderline significantly. Table 3 showed the results from the multivariate log-binomial regression model. The poor workplace ventilation (APR: 1.26; 95\% CI: 1.03-1.52) was found to be independent risk factor and $\geq 4$ days of every week of intake of fruit (APR: 0.81; 95\% CI: 0.65-0. 99) was found to be independent protective factor
Table 1 Characteristics of study participants received the QFT test in the Hospital of Occupational Diseases $(n=244)$

\begin{tabular}{|c|c|}
\hline Characteristics & $\mathrm{n}(\%)$ or median(IQR) \\
\hline \multicolumn{2}{|l|}{ Sex } \\
\hline Male & 244(100.0) \\
\hline Female & $0(0.0)$ \\
\hline Age(years) & $67(64-75)$ \\
\hline$<60$ & $20(8.2)$ \\
\hline $60 \sim 70$ & $125(51.2)$ \\
\hline$\geq 70$ & 99(40.6) \\
\hline \multicolumn{2}{|l|}{ Ethnic origin } \\
\hline Ethnic Han & 242(99.2) \\
\hline Other ethnic groups & $2(0.8)$ \\
\hline $\mathrm{BMI}(\mathrm{kg} / \mathrm{m} 2)^{\mathrm{a}}$ & $25.6(23.5-27.3)$ \\
\hline $18.5 \sim 25$ & $99(40.7)$ \\
\hline$\geq 25$ & 144(59.3) \\
\hline \multicolumn{2}{|l|}{ Highest education level } \\
\hline Primary school or lower & 123(50.4) \\
\hline Middle school & 95(38.9) \\
\hline High school & 26(10.7) \\
\hline \multicolumn{2}{|l|}{ Marital status } \\
\hline Married & 229(93.9) \\
\hline Divorced or Widowed & 15(6.1) \\
\hline Personal income per month (RMB) & $3050(3000-3700)$ \\
\hline$<3000$ & 29(11.9) \\
\hline $3000 \sim 4000$ & 178(72.9) \\
\hline$\geq 4000$ & $37(15.2)$ \\
\hline Family income per head per month(RMB) ${ }^{a}$ & $4500(3500-6000)$ \\
\hline$<6000$ & 137(67.2) \\
\hline $6000 \sim 10,000$ & $49(24.0)$ \\
\hline$\geq 10,000$ & 18(8.8) \\
\hline \multicolumn{2}{|l|}{ Place of Birth } \\
\hline City & 23(9.4) \\
\hline Countryside & 221(90.6) \\
\hline
\end{tabular}

QFT QuantiFERON-TB Gold In-Tube, IQR interquartile range, $B M I$ body mass index, $R M B$ Renminbi

a Sum may not equal the total because of missing data

associated with a positive QFT result. Job category was not associated with a positive QFT result.

\section{Discussion}

In this study, we found that the prevalence of LTBI among CWP patients in China was $66.4 \%$ based on the QFT. This was considerably higher than that reported in a community-based study conducted in rural China (13\%20\%) [13]. To date, besides a study that investigated the prevalence of LTBI among aged underground hard coal miners using IGRAs in Germany and reported positive 
Table 2 Bivariate analyses of factors associated with QFT positivity among study participants $(n=242)$

\begin{tabular}{|c|c|c|c|c|}
\hline \multirow[t]{3}{*}{ Factors } & \multicolumn{2}{|l|}{ QFT test } & \multirow{3}{*}{$\begin{array}{l}\text { Prevalence ratio } \\
(95 \% \mathrm{Cl})\end{array}$} & \multirow{3}{*}{$\begin{array}{l}p- \\
\text { value }\end{array}$} \\
\hline & Negative & Positive & & \\
\hline & $80(33.1 \%)$ & $162(66.9 \%)$ & & \\
\hline \multicolumn{5}{|l|}{ Socio-demographic characteristics } \\
\hline \multicolumn{5}{|l|}{ Age (years) } \\
\hline$<60$ & $9(45.0 \%)$ & $11(55.0 \%)$ & 1 & - \\
\hline $60-$ & $43(34.4 \%)$ & $82(65.6 \%)$ & $1.19(0.79-1.81)$ & 0.407 \\
\hline$\geq 70$ & $28(28.9 \%)$ & $69(71.1 \%)$ & $1.29(0.85-1.96)$ & 0.226 \\
\hline \multicolumn{5}{|l|}{$\operatorname{BMI}\left(\mathrm{kg} / \mathrm{m}^{2}\right)^{\mathrm{a}}$} \\
\hline $18.5-$ & $35(36.1 \%)$ & $62(63.9 \%)$ & 1 & - \\
\hline$\geq 25$ & $44(30.6 \%)$ & $100(69.4 \%)$ & $1.09(0.90-1.31)$ & 0.379 \\
\hline \multicolumn{5}{|l|}{ Highest education level } \\
\hline Primary school or lower & $43(35.5 \%)$ & $78(64.5 \%)$ & 1 & - \\
\hline Middle school & $28(29.5 \%)$ & $67(70.5 \%)$ & $1.09(0.91-1.32)$ & 0.342 \\
\hline High school & $9(39.1 \%)$ & $17(73.9 \%)$ & $1.01(0.74-1.38)$ & 0.928 \\
\hline \multicolumn{5}{|l|}{ Marital status } \\
\hline Married & $73(32.0 \%)$ & $155(68.0 \%)$ & 1 & - \\
\hline Divorced or Widowed & $7(50.0 \%)$ & $7(50.0 \%)$ & $0.73(0.43-1.25)$ & 0.257 \\
\hline \multicolumn{5}{|c|}{ Personal income per month (RMB) } \\
\hline$<3000$ & $7(24.1 \%)$ & $22(75.9 \%)$ & 1 & - \\
\hline $3000-$ & $60(34.1 \%)$ & $116(65.9 \%)$ & $0.87(0.69-1.09)$ & 0.233 \\
\hline$\geq 4000$ & $13(35.1 \%)$ & $24(64.9 \%)$ & $0.86(0.62-1.17)$ & 0.323 \\
\hline \multicolumn{5}{|c|}{ Family income per head per month (RMB) ${ }^{a}$} \\
\hline$<6000$ & $45(33.3 \%)$ & $90(66.7 \%)$ & 1 & - \\
\hline $6000-$ & $16(32.7 \%)$ & $33(67.3 \%)$ & $1.01(0.80-1.27)$ & 0.931 \\
\hline$\geq 10,000$ & $5(27.8 \%)$ & $13(72.2 \%)$ & $1.08(0.79-1.48)$ & 0.613 \\
\hline \multicolumn{5}{|l|}{ Place of birth } \\
\hline City & $7(30.4 \%)$ & $16(69.6 \%)$ & 1 & - \\
\hline Countryside & 73(33.3\%) & $146(66.7 \%)$ & $0.96(0.72-1.28)$ & 0.771 \\
\hline \multicolumn{5}{|l|}{ Occupational factors } \\
\hline \multicolumn{5}{|l|}{ Stages of CWP } \\
\hline । & $62(31.3 \%)$ & $136(68.7 \%)$ & 1.00 & - \\
\hline$\|$ & $16(39.0 \%)$ & $25(61.0 \%)$ & $0.89(0.68-1.15)$ & 0.374 \\
\hline III & $2(66.7 \%)$ & $1(33.3 \%)$ & $0.48(0.10-2.41)$ & 0.377 \\
\hline \multicolumn{5}{|l|}{ Job category } \\
\hline Transport and helping & $9(60.0 \%)$ & $6(40.0 \%)$ & 1.00 & - \\
\hline Mining & $31(36.5 \%)$ & $54(63.5 \%)$ & $1.59(0.84-3.01)$ & 0.157 \\
\hline Tunneling & $16(25.4 \%)$ & $47(74.6 \%)$ & $1.87(0.10-3.52)$ & 0.055 \\
\hline Both tunneling and mining & $24(30.4 \%)$ & $55(69.6 \%)$ & $1.74(0.92-3.29)$ & 0.088 \\
\hline \multicolumn{5}{|l|}{ Years of work } \\
\hline $10-$ & $4(40 \%)$ & $6(60.0 \%)$ & 1.00 & - \\
\hline $20-$ & $21(27.6 \%)$ & $55(72.4 \%)$ & $1.21(0.71-2.04)$ & 0.484 \\
\hline $30-$ & 47(33.3\%) & $94(66.7 \%)$ & $1.11(0.66-1.87)$ & 0.691 \\
\hline $40-$ & $8(53.3 \%)$ & $7(46.7 \%)$ & $0.78(0.37-1.63)$ & 0.506 \\
\hline
\end{tabular}

Dust exposure period 
Table 2 Bivariate analyses of factors associated with QFT positivity among study participants $(n=242)$ (Continued)

\begin{tabular}{|c|c|c|c|c|}
\hline \multirow[t]{3}{*}{ Factors } & \multicolumn{2}{|l|}{ QFT test } & \multirow{3}{*}{$\begin{array}{l}\text { Prevalence ratio } \\
(95 \% \mathrm{Cl})\end{array}$} & \multirow{3}{*}{$\begin{array}{l}p- \\
\text { value }\end{array}$} \\
\hline & \multirow{2}{*}{$\begin{array}{l}\text { Negative } \\
80(33.1 \%)\end{array}$} & \multirow{2}{*}{$\begin{array}{l}\text { Positive } \\
162(66.9 \%)\end{array}$} & & \\
\hline & & & & \\
\hline $1940-$ & $13(40.6 \%)$ & 19(59.4\%) & 1.00 & - \\
\hline $1960-$ & $47(29.9 \%)$ & $110(70.1 \%)$ & $1.18(0.87-1.60)$ & 0.286 \\
\hline $1980-$ & $20(37.7 \%)$ & $33(62.3 \%)$ & $1.05(0.74-1.50)$ & 0.793 \\
\hline \multicolumn{5}{|c|}{ Age at first dust exposure } \\
\hline$<18$ & $9(33.3 \%)$ & $18(66.7 \%)$ & 1.00 & - \\
\hline $18-29$ & $63(32.8 \%)$ & $129(67.2 \%)$ & $1.01(0.76 \sim 1.34)$ & 0.286 \\
\hline$\geq 30$ & $8(34.8 \%)$ & $15(65.2 \%)$ & $0.98(0.66 \sim 1.46)$ & 0.793 \\
\hline \multicolumn{5}{|c|}{ Duration of dust exposure(years) } \\
\hline$<10$ & $1(14.3 \%)$ & $6(85.7 \%)$ & 1.00 & - \\
\hline $10-$ & $21(38.9 \%)$ & $33(61.1 \%)$ & $0.71(0.49-1.03)$ & 0.073 \\
\hline $20-$ & $33(34.4 \%)$ & $63(65.6 \%)$ & $0.77(0.55 \sim 1.07)$ & 0.119 \\
\hline $30-$ & $25(29.4 \%)$ & $60(70.6 \%)$ & $0.82(0.59-1.15)$ & 0.252 \\
\hline \multicolumn{5}{|c|}{ Environmental factors } \\
\hline \multicolumn{5}{|c|}{ Workplace ventilation } \\
\hline Well & $46(41.1 \%)$ & $66(58.9 \%)$ & 1.00 & - \\
\hline Poor & $34(26.2 \%)$ & $96(73.8 \%)$ & $1.25(1.04-1.51)$ & 0.017 \\
\hline \multicolumn{5}{|l|}{ Accommodation } \\
\hline Building & $36(32.1 \%)$ & $76(67.9 \%)$ & 1.00 & - \\
\hline Bungalow & $44(33.8 \%)$ & $86(66.2 \%)$ & $0.98(0.82-1.16)$ & 0.779 \\
\hline \multicolumn{5}{|l|}{ Living space $^{b}$} \\
\hline$<20$ & $21(29.2 \%)$ & $51(70.8 \%)$ & 1.00 & - \\
\hline $20-40$ & $35(34.0 \%)$ & $68(66.0 \%)$ & $0.93(0.761-1.142)$ & 0.497 \\
\hline $40-$ & 6(23.1\%) & $20(76.9 \%)$ & $1.10(0.873-1.381)$ & 0.424 \\
\hline \multicolumn{5}{|l|}{ Behavioral factors } \\
\hline \multicolumn{5}{|l|}{ Smoking } \\
\hline Never & $12(34.3 \%)$ & $23(65.7 \%)$ & 1.00 & - \\
\hline Once & $45(38.5 \%)$ & $72(61.5 \%)$ & $0.94(0.71-1.24)$ & 0.497 \\
\hline Occasionally & $4(66.7 \%)$ & $2(33.3 \%)$ & $0.51(0.16-1.61)$ & 0.424 \\
\hline Frequently & $19(22.6 \%)$ & 65(77.4\%) & $1.18(0.90-1.54)$ & 0.424 \\
\hline \multicolumn{5}{|c|}{ Start smoking age } \\
\hline$<18$ & $14(31.8 \%)$ & $30(68.2 \%)$ & 1.00 & - \\
\hline$\geq 18$ & $51(32.3 \%)$ & $107(67.7 \%)$ & $0.99(0.79-1.25)$ & 0.954 \\
\hline \multicolumn{5}{|l|}{ Smoking index ${ }^{c}$} \\
\hline 0 & 12(34.3) & $23(65.7)$ & 1 & - \\
\hline$>0$ & $21(36.2)$ & $37(63.8)$ & $0.99(0.73-1.35)$ & 0.954 \\
\hline $15-$ & 21(29.6) & $50(70.4)$ & $1.09(0.82-1.44)$ & 0.566 \\
\hline $30-$ & 23(31.9) & $49(68.1)$ & $1.05(0.79-1.40)$ & 0.741 \\
\hline \multicolumn{5}{|l|}{ Smoking years } \\
\hline$<10$ & 7(58.3\%) & $5(41.7 \%)$ & 1.00 & - \\
\hline $10-$ & $17(34.0 \%)$ & $33(66.0 \%)$ & $1.58(0.79-3.19)$ & 0.197 \\
\hline$\geq 30$ & $40(29.0 \%)$ & $98(71.0 \%)$ & $1.70(0.87-3.36)$ & 0.123 \\
\hline
\end{tabular}

Drinking 
Table 2 Bivariate analyses of factors associated with QFT positivity among study participants $(n=242)$ (Continued)

\begin{tabular}{|c|c|c|c|c|}
\hline \multirow[t]{3}{*}{ Factors } & \multicolumn{2}{|l|}{ QFT test } & \multirow{3}{*}{$\begin{array}{l}\text { Prevalence ratio } \\
(95 \% \mathrm{Cl})\end{array}$} & \multirow{3}{*}{$\begin{array}{l}p- \\
\text { value }\end{array}$} \\
\hline & \multirow{2}{*}{$\begin{array}{l}\text { Negative } \\
80(33.1 \%)\end{array}$} & \multirow{2}{*}{$\begin{array}{l}\text { Positive } \\
162(66.9 \%)\end{array}$} & & \\
\hline & & & & \\
\hline Never & 19(27.9\%) & 49(72.1\%) & 1.00 & - \\
\hline Once & $16(35.6 \%)$ & $29(64.4 \%)$ & $0.89(0.69-1.16)$ & 0.405 \\
\hline Occasionally & 13(30.2\%) & $30(69.8 \%)$ & $0.97(0.76-1.24)$ & 0.797 \\
\hline Frequently & $32(37.2 \%)$ & $54(62.8 \%)$ & $0.87(0.70-1.09)$ & 0.220 \\
\hline \multicolumn{5}{|l|}{ Drinking index ${ }^{d}$} \\
\hline 0 & $32(32.3)$ & $67(67.7)$ & 1 & - \\
\hline $1-$ & 10(28.6) & 25(71.4) & $1.05(0.82-1.36)$ & 0.672 \\
\hline $50-$ & 15(30.6) & $34(69.4)$ & $1.02(0.81-1.29)$ & 0.832 \\
\hline $100-$ & 19(39.6) & $29(60.4)$ & $0.89(0.68-1.16)$ & 0.404 \\
\hline \multicolumn{5}{|c|}{ Days of every week of intake of fruits } \\
\hline$<1$ & $7(18.4 \%)$ & $31(81.6 \%)$ & 1.00 & - \\
\hline $1-3$ & $27(35.5 \%)$ & $49(64.5 \%)$ & $0.79(0.63-0.99)$ & 0.041 \\
\hline$\geq 4$ & $34(35.8 \%)$ & $61(64.2 \%)$ & $0.79(0.64-0.97)$ & 0.028 \\
\hline \multicolumn{5}{|c|}{ Days of every week of physical exercise } \\
\hline$<1$ & $2(40.0 \%)$ & $3(60.0 \%)$ & 1.00 & - \\
\hline $1-$ & $11(28.9 \%)$ & $27(71.1 \%)$ & $1.18(0.56-2.49)$ & 0.656 \\
\hline 7 & 60(33.3\%) & $120(66.7 \%)$ & $1.11(0.54-2.29)$ & 0.775 \\
\hline \multicolumn{5}{|c|}{ Length of sleeping (hour) } \\
\hline$<6$ & $24(36.9 \%)$ & $41(63.1 \%)$ & 1.00 & - \\
\hline 6- & $34(29.8 \%)$ & $80(70.2 \%)$ & $1.11(0.89-1.39)$ & 0.345 \\
\hline$\geq 8$ & $22(34.9 \%)$ & $41(65.1 \%)$ & $1.03(0.80-1.34)$ & 0.813 \\
\hline \multicolumn{5}{|c|}{ History of BCG vaccination } \\
\hline No & $72(33.2 \%)$ & $145(66.8 \%)$ & 1.00 & - \\
\hline Yes & $8(32.0 \%)$ & $17(68.0 \%)$ & $1.02(0.77-1.35)$ & 0.904 \\
\hline \multicolumn{5}{|c|}{ The family history of tuberculosis } \\
\hline No & $78(33.5 \%)$ & $155(66.5 \%)$ & 1.00 & - \\
\hline Yes & $2(22.2 \%)$ & $7(77.8 \%)$ & $1.17(0.82-1.68)$ & 0.396 \\
\hline \multicolumn{5}{|c|}{ Exposure history of tuberculosis } \\
\hline No & $77(33.8 \%)$ & $151(66.2 \%)$ & 1.00 & - \\
\hline Yes & $3(21.4 \%)$ & $11(78.6 \%)$ & $1.19(0.89-1.58)$ & 0.246 \\
\hline
\end{tabular}

QFT QuantiFERON-TB Gold In-Tube, Cl Confidence Interval

a Sum may not equal the total because of missing data

biving space: average per-capita living space $\left(\mathrm{m}^{2}\right)$

'Smoking index(pack-years): average number of packs of cigarettes smoked per day multiplied by the number of smoking years

${ }^{d}$ Drinking index(50 g.year):grams of alcohol consumed daily multiplied by years of drinking

rates of 46.6\% (QFT) and 61.0\% (T-SPOT) [11], no studies have reported the prevalence of LTBI among CWP patients in the rest of the world. As for occupational studies, a few reports employed the IGRA in healthcare workers and detected positive rates of 9.9\% (QFT) in Japan [14], 10.6\% (QFT) in Malaysia [15], 25\% (QFT) in Italy [16], 40.8\% (QFT) in Russia [17], 46\% (QFT) in Georgia [18], 76.7\% (QFT) and 65.7\% (A.TB, a Mycobacterium tuberculosis-specific cell-mediated immune response detection kit) in China [8], and 46.0\% (QFT) among village doctors in China [19].
The prevalence of LTBI in healthcare workers therefore varied greatly between countries, with a much higher LTBI rate in China than in any of the other countries.

In our study, 29.8\% of CWP patients had a history of previous TB. This finding was in agreement with a previous study among 1107 patients in a coal mine industry group [20], which showed the total rate of pneumoconiosis complicated with tuberculosis was $30.5 \%$.The prevalence $(66.4 \%)$ of LTBI among CWP patients in our study was higher than among village doctors (46.0\%) [19] but 
Table 3 Multivariate log-binomial regression analysis of factors associated with QFT positivity among study participants $(n=242)$

\begin{tabular}{|c|c|c|c|c|}
\hline Variable & Adjust prevalence ratio & $95 \% \mathrm{Cl}$ & $\mathrm{p}$-value & p-trend \\
\hline \multicolumn{5}{|l|}{ Job category } \\
\hline Transport and helping & 1.00 & - & & \\
\hline Mining & 1.49 & $0.80-2.76$ & 0.207 & \\
\hline Tunneling & 1.68 & $0.91-3.10$ & 0.095 & \\
\hline Both tunneling and mining & 1.70 & $0.92-3.13$ & 0.090 & \\
\hline \multicolumn{5}{|l|}{ Workplace ventilation } \\
\hline Well & 1.00 & - & & \\
\hline Poor & 1.26 & $1.03-1.52$ & 0.022 & \\
\hline \multicolumn{5}{|c|}{ Days of every week of intake of fruits } \\
\hline$<1$ & 1.00 & - & - & 0.033 \\
\hline $1-3$ & 0.82 & $0.66-1.03$ & 0.089 & \\
\hline$\geq 4$ & 0.81 & $0.65-0.99$ & 0.049 & \\
\hline
\end{tabular}

QFT QuantiFERON-TB Gold In-Tube, Cl Confidence Interval

lower than that among healthcare workers (76.7\%) in China [8]. This suggested that those exposed to TB via their occupation have a higher risk of LTBI in China. In our study, poor ventilation condition was positive associated with QFT positivity. These findings were in agreement with previous active TB studies [21, 22] that demonstrated that poor ventilation condition was vital risk factor for CWP with active TB. It is therefore clear that careful monitoring and dust control measures need to be improved in workplaces to ensure the safety of workers. Furthermore, physical examination and QFT tests should be performed regularly to facilitate the early detection of LTBI with CWP. Active treatment and better management of patients are required to reduce the risk of LTBI with CWP. We also found regular intake of fruit ( $\geq 4$ days of every week) was associated with LTBI among CWP. Few studies have reported whether intake of fruits is significantly associated with LTBI. A casecontrol study in a community that investigated relation between specific dietary and susceptibility of tuberculosis, concluded that an inadequate intake of fruits and vegetables was associated with an increased risk of new tuberculosis infection [23]. However, large prospective and interventional studies are needed to confirm the effect of fruits.

To date, most community-based studies of LTBI have shown that a positive QFT result is associated with age. This has been shown in studies in rural China [13] and among healthcare workers [14, 24, 25]. However, in our study, this correlation was not detected among CWP patients. This may be explained by the fact that our study population predominantly comprised older participants who had survived CWP and who were all over 40 years of age (median age: 67 years). Studies have demonstrated a high risk of $M$. tuberculosis infection among individuals in close contact with TB cases [13, 22, 26]. However, in the present study, the positivity of QFT was not affected by a previous history of close contact with TB patients, and this was in agreement with the previous findings from some studies of healthcare workers [16, $25,27]$. This could be explained by the fact that some of the CWP patients in our study may have been unknowingly exposed to TB either within their working environment or in the community. Our study did not confirm the potential protective effect of BCG vaccination in CWP patients. This finding was consistent with the results of studies carried out in populations involved in other occupations [27, 28]. This finding may be explained by the fact that China has a high TB burden and a high coverage of BCG vaccination. However, BCG vaccination has been included in the national immunization program in China since 1978, so there would be poor vaccination coverage in participants born before that time possibly explaining the lack of impact of BCG vaccination among our study population. There is evidence showing that smoking is significantly associated with silicosis $[29,30]$ and with TB [22, 31, 32]; however, few studies have verified whether smoking is significantly associated with LTBI among CWP patients. In our study, smoking was not associated with LTBI.

\section{Limitations}

There are several limitations of our study that should be addressed. Firstly, the sample size was limited. Secondly, participants were surviving CWP patients and the majority was over 60 years of age. Therefore, our study population is not representative of the general CWP population in China. Thirdly, the majority of participants had retired so it was difficult to verify their potential occupational contact with TB cases, leading to possible recall bias. 


\section{Conclusions}

This study showed that the high prevalence of LTBI among CWP patients in China. We found that poor workplace ventilation could be a risk factor and intake of fruits regularly ( $\geq 4$ days of every week) found to be a protective factor. In response, specific measures need to be implemented including the proactive reduction of workers' exposure to coal dust by improving ventilation conditions and regular screening of those at high risk of CWP to ensure the early detection of LTBI. Large studied should be studied for the effect intake of fruits regularly on the risk of LTBI.

\section{Additional file}

Additional file 1: The results of QFT among 244 CWP patients. (XLSX $24 \mathrm{~kb}$ )

\section{Abbreviations}

APR: Adjusted prevalence ratio; BCG: Bacillus Calmette - Guerin; BMI: Body mass index; CWP: Coal workers' pneumoconiosis; ELISA: Enzyme-linked immunosorbent assay; IFN- $\gamma$ : Interferon- $\gamma$; IGRAs: IFN- $\gamma$ release assays; IQR: Interquartile range; LTBI: Latent tuberculosis infection; OD: Optical density; OR: Odds ratio; Cl: confidence interval; PR: Prevalence ratio; QFT: QuantiFERON-TB Gold In-Tube; TB: Tuberculosis; TST: Tuberculin skin test

\section{Acknowledgements}

We are very grateful to the study participants from the health centers. We would like to thank the nurses and Shilong hospital's staff at the National Occupational Health Centre for their technical assistance in the physical and clinical examinations. We would like to thank Dr. Wei Chen for valuable advice, and Dr. Chunguang Ding and Ms. Zhi Ying for their assistance with the laboratory work.

\section{Funding}

Research program on occupational poisoning and occupational lung disease.

\section{Availability of data and materials}

All data generated or analysed during this study was included in this published article and its supplementary information files. Dataset don't contain any direct or indirect confidential information of participants. The analysis software of QFT test results can be achieved online at http:// www.quantiferon.com/products/quantiferon-cmv/technical-info/.

\section{Authors' contributions}

YJ: conceived and wrote the study proposal, recruited and interviewed study participants, QFT testing, performed statistical analysis and wrote the manuscript. CGD, KW: recruited and interviewed study participants. HQW, JFZ, JGF \& TL: participated in conceiving the study proposal and revised the manuscript. All authors agreed to accountable for all aspects of the study and read and approved the final manuscript.

\section{Ethics approval and consent to participate}

The study protocol (reference number: 159) was approved by the Ethical Clearance Committee of the National Institute of Occupational Health and Poison Control of the Chinese Center for Disease Control and Prevention on December 27, 2013. The aim and content of this study and the possible effects of tests were explained to each of the study participants and written consent was obtained. Blood samples were collected under aseptic conditions by experienced nurses.

\section{Consent for publication}

For all details of manuscript relating to an individual person, written informed consent for the publication of these details were obtained from the study participants. All authors read and approved the final manuscript.

\section{Competing interests}

The authors declare that they have no competing interests.

\section{Publisher's Note}

Springer Nature remains neutral with regard to jurisdictional claims in published maps and institutional affiliations.

\section{Author details}

${ }^{1}$ National Institute of Occupational Health and Poison Control, Chinese Center for Disease Control and Prevention, Beijing, China. ${ }^{2}$ Department of Infectious Disease, Taizhou Center for Disease Control and Prevention, Taizhou, China. ${ }^{3}$ Research Center for Occupational Safety and Health, State Administration of Work Safety, Beijing, China.

Received: 26 July 2017 Accepted: 26 March 2018

Published online: 11 April 2018

\section{References}

1. About 2014 the occupational-disease-prevention work situation. In: National Health and Family Planning Commission of the People's Republic of China; 2015.http://www.nhfpc.gov.cn/jkj/s5899t/201512/ c5a99f823c5d4dd48324c6be69b7b2f9.shtml. Accessed 8 Apr 2018.

2. About 2013 the occupational-disease-prevention work situation. In: National Health and Family Planning Commission of the People's Republic of China; 2014. http://www.nhfpc.gov.cn/jkj/s5899t/201406/ ed8ed220d0b74010bcb6dcd8e340f4fb.shtml. Accessed 8 Apr 2018.

3. O'Neill RP, Robin ED. Relations of pneumoconiosis and pulmonary tuberculosis. Arch Environ Health Int J. 1964;8(6):873-81.

4. Getahun H, Matteelli A, Chaisson RE, Raviglione M. Latent Mycobacterium tuberculosis infection. N Engl J Med. 2015;372(22):2127-35.

5. Schmit KM, Wansaula Z, Pratt R, Price SF, Langer AJ. Tuberculosis - United States, 2016. MMWR Morb Mortal Wkly Rep. 2017;66(11):289.

6. Guidelines on the Management of Latent Tuberculosis Infection. In. Geneva: World Health Organization: World Health Organization; 2015.

7. Government of Canada, Public Health Agency of Canada. Recommendations on Interferon Gamma Release Assays for the Diagnosis of Latent Tuberculosis Infection - 2010 Update. Can Commun Dis Rep (CCDR). 2010;35:ACS-5.

8. Wei Z, Yang M, Quan B, Wang Y, Wu Y, Ji B. Prevalence of latent tuberculosis infection among healthcare workers in China as detected by two interferon-gamma release assays. J Hosp Infect. 2013;84(4):323-5.

9. Dorman SE, Belknap R, Graviss EA, Reves R, Schluger N, Weinfurter P, Wang $Y$, Cronin W, Hirsch-Moverman Y, Teeter LD, et al. Interferon-gamma release assays and tuberculin skin testing for diagnosis of latent tuberculosis infection in healthcare workers in the United States. Am J Respir Crit Care Med. 2014;189(1):77-87.

10. Lamberti M, Muoio M, Monaco MG, Uccello R, Sannolo N, Mazzarella G, Garzillo EM, Arnese A, La Cerra G, Coppola N. Prevalence of latent tuberculosis infection and associated risk factors among 3,374 healthcare students in Italy. J Occup Med Toxicol. 2014;9(1):34.

11. Ringshausen FC, Nienhaus A, Schablon A, Torres Costa J, Knoop H, Hoffmeyer F, Bunger J, Merget R, Harth V, Schultze-Werninghaus G, et al. Frequent detection of latent tuberculosis infection among aged underground hard coal miners in the absence of recent tuberculosis exposure. PLoS One. 2013;8(12):e82005.

12. Deddens JA, Petersen MR. Approaches for estimating prevalence ratios. Occup Environ Med. 2008;65(7):481. 501-486

13. Gao L, Lu W, Bai L, Wang X, Xu J, Catanzaro A, Cárdenas V, Li X, Yang Y, Du $J$, et al. Latent tuberculosis infection in rural China: baseline results of a population-based, multicentre, prospective cohort study. Lancet Infect Dis. 2015;15(3):310-9.

14. Harada N, Nakajima Y, Higuchi K, Sekiya Y, Rothel J, Mori T. Screening for tuberculosis infection using whole-blood interferon- $\gamma$ and Mantoux testing among Japanese healthcare workers. Infect Control Hosp Epidemiol. 2006; 27(5):442-8

15. Rafiza S, Rampal KG, Tahir A. Prevalence and risk factors of latent tuberculosis infection among health care workers in Malaysia. BMC Infect Dis. 2011;11:19.

16. Olivieri R, Scarnera S, Ciabattini A, De Vuono G, Manzi P, Pozzi G, Battista G, Medaglini D. Using IFN-gamma release assay to confirm tuberculin skin test improves the screening of latent tuberculosis infection in Italian healthcare workers. J Occup Med Toxicol. 2016;11:29. 
17. Drobniewski F, Balabanova Y, Zakamova E, Nikolayevskyy V, Fedorin I. Rates of latent tuberculosis in health care staff in Russia. PLoS Med. 2007:4(2):e55.

18. Whitaker JA, Mirtskhulava V, Kipiani M, Harris DA, Tabagari N, Kempker RR, Blumberg HM. Prevalence and incidence of latent tuberculosis infection in georgian healthcare workers. PLoS One. 2013;8(3):e58202.

19. He G, Li Y, Zhao F, Wang L, Cheng S, Guo H, Klena JD, Fan H, Gao F, Gao F, et al. The prevalence and incidence of latent tuberculosis infection and its associated factors among village doctors in China. PLoS One. 2015;10(5): e0124097.

20. Fan HM, Yuan JX, Ying-Jun XU. Investigation on pneumoconiosis complicated with tuberculosis among 1107 patients in a coal mine industry group. China Occup Med. 2007;35(5):386-8.

21. Nardell EA. Indoor environmental control of tuberculosis and other airborne infections. Indoor Air. 2016;26(1):79-87.

22. Gebrecherkos T, Gelaw B, Tessema B. Smear positive pulmonary tuberculosis and HIV co-infection in prison settings of North Gondar zone, Northwest Ethiopia. BMC Public Health. 2016;16(1):1091.

23. Fox GJ, Lee RS, Lucas M, Khan FA, Proulx JF, Hornby K, Jung S, Benedetti A, Behr MA, Menzies D, Inadequate Diet I. Associated with acquiring Mycobacterium tuberculosis infection in an Inuit community. A case-control study. Ann Am Thorac Soc. 2015;12(8):1153-62.

24. Pai M, Gokhale K, Joshi R, Dogra S, Kalantri S, Mendiratta DK, Narang P, Daley CL, Granich RM, Mazurek GH. Mycobacterium tuberculosis infection in health care workers in rural India: comparison of a whole-blood interferon gamma assay with tuberculin skin testing. JAMA. 2005;293(22):2746-55.

25. Hung WT, Lee SS, Sy CL, Wu KS, Chen JK, Tsai HC, Chen YS. Prevalence of latent tuberculosis infection in BCG-vaccinated healthcare workers by using an interferon-gamma release assay and the tuberculin skin test in an intermediate tuberculosis burden country. J Microbiol Immunol Infect. 2015; 48(2):147-52.

26. Hu Y, Zhao Q, Wu L, Wang W, Yuan Z, Xu B. Prevalence of latent tuberculosis infection and its risk factors in schoolchildren and adolescents in shanghai, China. Eur J Pub Health. 2013;23(6):1064-9.

27. Hussain $\mathrm{H}$, Akhtar S, Nanan D. Prevalence of and risk factors associated with Mycobacterium tuberculosis infection in prisoners, north west Frontier Province, Pakistan. Int J Epidemiol. 2003;32(5):794-9.

28. Durando P, Sotgiu G, Spigno F, Piccinini M, Mazzarello G, Viscoli C, Copello F, Poli A, Ansaldi F, Icardi G. Latent tuberculosis infection and associated risk factors among undergraduate healthcare students in Italy: a cross-sectional study. BMC Infect Dis. 2013;13:443.

29. Hessel PA, Gamble JF, Nicolich M. Relationship between silicosis and smoking. Scand J Work Environ Health. 2003;29(5):329-36.

30. Tse LA, Yu IT, Qiu H, Leung CC. Joint effects of smoking and silicosis on diseases to the lungs. PLoS One. 2014:9(8):e104494.

31. Smith GS, Van Den Eeden SK, Baxter R, Shan J, Van Rie A, Herring AH, Richardson DB, Emch M, Gammon MD. Cigarette smoking and pulmonary tuberculosis in northern California. J Epidemiol Community Health. 2015; 69(6):568-73.

32. Rao VG, Bhat J, Yadav R, Muniyandi M, Bhondeley MK, Sharada MA, Chadha VK, Wares DF. Tobacco smoking: a major risk factor for pulmonary tuberculosis-evidence from a cross-sectional study in Central India. Trans R Soc Trop Med Hyg. 2014;108(8):474-81.

\section{Submit your next manuscript to BioMed Central and we will help you at every step:}

- We accept pre-submission inquiries

- Our selector tool helps you to find the most relevant journal

- We provide round the clock customer support

- Convenient online submission

- Thorough peer review

- Inclusion in PubMed and all major indexing services

- Maximum visibility for your research

Submit your manuscript at www.biomedcentral.com/submit

CBiomed Central 